\title{
The Energy Transition and the Advent of Hydrogen Economy
}

\author{
Matilde Pietrafesa
}

DICEAM, Mediterranea University, Reggio Calabria 89121, Italy

Corresponding Author Email: matilde.pietrafesa@unirc.it

https://doi.org/10.18280/ti-ijes.640103

Received: 7 January 2020

Accepted: 18 January 2020

\section{Keywords:}

climate change, sustainable energy, paradigm decarbonization, renewable energy sources, hydrogen and fuel cells

\begin{abstract}
Climate change according to almost all experts is a consolidated reality; the responsibility for these changes in the terrestrial ecosystem is largely attributable to man and in particular to activities related to the use of fossil fuels and deforestation.

In order to deal with these emergencies, in the near future a new sustainable energy paradigm should be established, fully implementing the decarbonization process and based on distributed micro-generation from renewable energy sources (RES), smart grids, energy storage and hydrogen.

Energy production from RES, characterized by variable temporal availability, unpredictable over time, can efficiently meet the needs if coupled with storage systems (mechanical, electrical, chemical, thermal, biological, etc.): it follows that thanks to its energy performance and its environmental sustainability, the interest in hydrogen as energy carrier (it is clean, versatile and has high combustion efficiency) is growing today. The paper illustrates the characteristics and properties of hydrogen, together with its production and storage techniques and its uses, highlighting how, thanks to its environmental sustainability, it could play the role of energy carrier of the future in the new decarbonized energy paradigm.
\end{abstract}

\section{CLIMATE CHANGE AND THE NEED FOR A NEW ENERGY PARADIGM}

Nowadays almost all climate experts agree that climate change is a consolidated reality, the responsibility for which is largely attributable to man, especially to activities related to the use of fossil fuels, which have caused upheavals of the terrestrial ecosystem, and deforestation.

The main among the bodies involved in climate change is the Intergovernmental Panel on Climate Change (IPCC), established in 1988 by the United Nations and the World Meteorological Organization (WMO), which is responsible for the scientific evaluation of these phenomena and their potential environmental and socio-economic impact.

Worldwide, the average earth temperature has increased by about $0.8^{\circ} \mathrm{C}$ since 1880 (Figure 1), while on the European continent there has been a greater raise (around $1.4{ }^{\circ} \mathrm{C}$ ), and a future increase of $4^{\circ} \mathrm{C}$ cannot be excluded.

IPCC has estimated in $2{ }^{\circ} \mathrm{C}$ the global average temperature increase, compared to the pre-industrial period, in order to avoid dramatic consequences for the planet [1]. Thus was born the need to take on shared commitments at an international level by directing the energy system on a virtuous path, started in December 2015 with the $21^{\text {st }}$ climate conference held in Paris (COP21) and the Agreement stipulated therein, and to assume the consequent actions necessary to implement it.

In Europe, member countries purchase oil from OPEC nations and Russia and still natural gas from Algeria, Norway and Russia itself. To limit this dependence on other states and to reduce carbon emissions, the European Union is incisively encouraging member countries towards a low carbon economy.

In particular EU, referring to the third point of the strategy contained in the Directive 2009/28/EC, so-called ClimateEnergy, on climate change and energy sustainability [2], has set three important objectives for 2020:

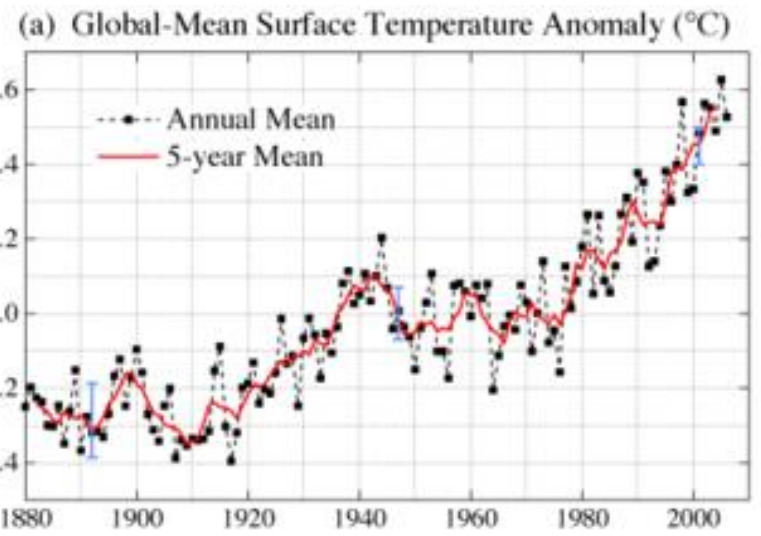

(b) 2006 Surface Temperature Anomaly $\left({ }^{\circ} \mathrm{C}\right)$

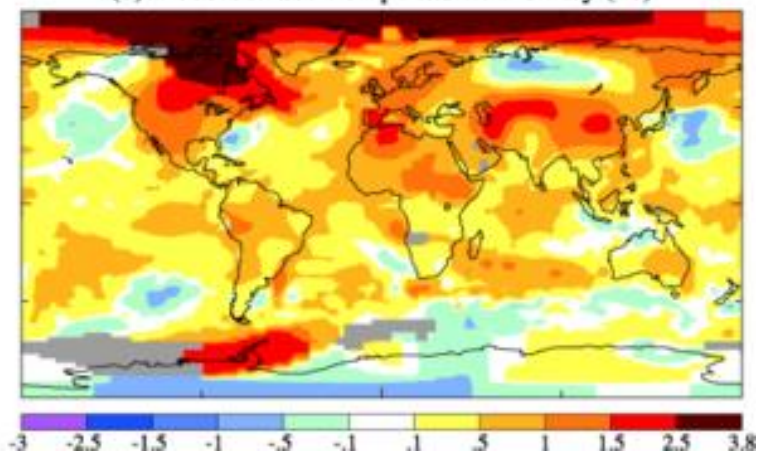

Figure 1. Temperature increase on planet surface 
- $20 \%$ greenhouse gas emissions reduction compared to 1990

- $20 \%$ energy production from renewable sources

- $20 \%$ reduction of primary energy consumption compared to 1990 .

As regards the framework to 2030, moreover, the Directive requires a further reduction of greenhouse gas emissions, bringing it to $40 \%$ compared to 1990 , and to $27 \%$ both the increase in the share of energy produced from renewable energy sources and in energy efficiency [3].

This would lead by 2050, according to the expected European road map [4], to $80 \%$ reductions of $\mathrm{CO}_{2}$ emissions related to the energy sector, including those of the transport sector, with electricity consumption from RES equal to $97 \%$, thus establishing a safe, competitive and decarbonized energy system.

\section{THE DECARBONIZATION PROCESS AND THE ENERGY TRANSITION TOWARDS A HYDROGEN ECONOMY}

\subsection{The decarbonization process}

The new and sustainable energy paradigm that should be established in the near future should fully implement a decarbonization process: the term indicates the change in the carbon-hydrogen ratio in the temporal succession of the different energy sources.

Wood, the primary energy source for most of human history, has the highest carbon-hydrogen ratio, with ten carbon atoms for each hydrogen atom; among fossil fuels coal has the highest ratio, with a value of $2: 1$, oil has one carbon atom for two of hydrogen, while natural gas has only one to four: this means that energy sources gradually used over time have emitted less carbon dioxide than the previous ones.

In the last one hundred and forty years, even if total $\mathrm{CO}_{2}$ emissions have continuously increased, the carbon emission per unit of primary energy globally consumed has decreased by about $0.3 \%$ per year: hydrogen would therefore represent the completion of the decarbonization path, being free of carbon atoms.

Its emergence as primary energy source of the future is therefore an indication of the end of the long dominance of hydrocarbon-based energy production.

In addition to the progressive elimination of carbon atoms, decarbonising has also meant the dematerialization of fuels, which have gone from solid (wood and coal) to liquid (petroleum), to gaseous (natural gas and hydrogen): hydrogen is in fact the lightest and most intangible form of energy and the most efficient in combustion for the same weight (three times that of oil).

The transition from solid energy forms to liquid and gaseous ones has also made flows into the system easier and more efficient: in pipelines oil travels faster than coal in railway wagons and gas in pipelines is in turn faster than oil; moreover it allowed flourishing of technologies, goods and services that tend to speed, efficiency, lightness and virtuality.

\subsection{The transition to a new energy paradigm}

From the above, it follows that the new energy paradigm that should be introduced in the coming decades will be based on the distributed micro-generation from renewable energy sources (small electricity production plants, isolated or interconnected, placed close to the end user), energy storage and hydrogen [5-8].

The production from RES, characterized by variable temporal availability, unpredictable over time, can in fact efficiently meet energy needs if coupled with storage systems (mechanical, electrical, chemical, thermal, biological, etc.): it follows that thanks to its energy performance and its environmental sustainability, the interest in hydrogen as energy carrier is growing today [9-11].

In particular, one of the most environmentally sustainable techniques for the accumulation of electricity produced from renewable energy consists in its use as a primary source for the production of electrolytic hydrogen, which is then converted back into electricity in fuel cells $[12,13]$

Production can take place both in large plants and in small generative units close to the end user and can affect multiple sectors (electrical production, transport, air conditioning, etc.) $[14,15]$

The fuel cells for its conversion could potentially produce electricity to meet the future needs of humanity, but triggering the transition from the era of fossil fuels to that of hydrogen will not be easy: producing hydrogen is still too expensive, so currently most fuel cells are powered by methane or other fossil fuels.

Furthermore, connecting millions of fuel cells to the grid will not be immediate and will require extremely sophisticated control and distribution mechanisms (smart grids), capable of regulating traffic both in normal and peak periods.

The new energy network will have to be interactive, equipped with integrated sensors and intelligent agents to provide real-time information on demand conditions, in order to allow the flow of electricity exactly where and when it is needed.

The problem of the current electricity distribution network, on the other hand, is that of being designed to ensure a oneway energy flow, from the producer to the end user, so transforming it into an interactive network of millions of small suppliers-users will require enormous efforts.

\subsection{Hydrogen as the energy carrier of the future}

In the 70s of the twentieth century, in conjunction with the first oil crisis, the need arose to identify and develop new energy frontiers, seeing hydrogen as an excellent opportunity to overcome the dependence linked to fossil fuels.

During the 1980s the end of the crisis and the collapse of the oil price caused a slowdown in the studies that were being carried out, but in the 1990s climate changes due to carbon emissions gave new impetus to research: as a consequence of this, since then the interest in the use of hydrogen is growing, thanks to its environmental sustainability and its energy performance (it is clean, versatile and has high combustion efficiency) [16-19].

Indeed:

- its combustion provides only water as a by-product (no greenhouse gases)

- it is suitable for stationary applications, in transports (vehicles, aircraft, boats), in air conditioning and portable equipment (PC, mobile phones)

- it can supply energy at all scales (from $\mu \mathrm{W}$ to $\mathrm{MW}$ )

- $1 \mathrm{~kg}$ of hydrogen contains the same amount of energy as $2.1 \mathrm{~kg}$ of natural gas or $2.8 \mathrm{~kg}$ of gasoline 
- it can be combined with gasoline, methanol, ethanol and natural gas, reducing nitrogen oxide emissions.

The disadvantage is its low energy density per unit of volume: hydrogen is in fact the fuel with the maximum energy density referred to the mass, but the minimum one referred to the volume.

\section{HYDROGEN: CHARACTERISTICS, PROPERTIES, BENEFITS}

Hydrogen is the lightest element of the periodic table and after helium it is the most difficult gas to liquefy $(\mathrm{T}=14.02$ $\mathrm{K})$. At atmospheric pressure and ambient temperature it appears as a colorless, odorless, flammable and practically insoluble in water gas. It is not found in the atomic state but in molecular form $\left(\mathrm{H}_{2}\right)$.

It is the most abundant element in the universe: very rare in its elemental state for its lightness (the gravitational attraction on Earth, less than that of stars and large planets, is insufficient to retain its very light molecules), it is particularly abundant in the combined state; it is found free in volcanic emanations, in oil sources, in fumaroles and in the atmosphere above $100 \mathrm{~km}$.

It is highly reactive and this makes it one of the main constituents of the plant and animal world: the human organism contains about $10 \%$ of its weight and in the field of organic chemistry there are known millions of compounds that contain it, from the simplest hydrocarbon (methane) to the complex carbohydrate proteins.

It directly combines with most non-metals and alkaline and alkaline earth metals; little active in cold, it is much more active in hot or in the presence of catalysts.

\subsection{Dangerousness}

Compared to other energy carriers, hydrogen diffuses and disperses faster, being much lighter than air. In the event of a leak, it is less subject to fire hazards than petrol or natural gas because it spreads rapidly diluting. In sufficient concentration, rather than exploding it tends to burn with a flame with a low level of radiant heat, without overheating the nearby areas. The spontaneous combustion temperature in air is $585^{\circ} \mathrm{C}$.

In the event of an explosion of cylinders, the main energy dissipation mechanism is a strong emission of sound energy, with the propagation of the flames upwards, while for LPG there is limited sound emission, with the propagation of the flames downwards and therefore greater danger.

\section{PRODUCTION}

Not being a primary form of energy but an energy carrier, in order to produce hydrogen it is necessary to start from the use of other energy resources.

It can be produced from the use of fossil or derived fuels, from biological material or from water [20]. Four types of sources can be distinguished:

- $\quad$ primary sources: hydrocarbons, coal, natural gas

- intermediate compounds: refinery products, methanol, ammonia

- $\quad$ alternative sources: biomass, biogas, algae, bacteria

- water.

World annual production of hydrogen is $5 \times 10^{11} \mathrm{Nm}^{3}$, equivalent to 44 million tons, $95 \%$ of which derives directly or indirectly from processes that use hydrocarbons.

$60 \%$ of it is obtained from the chemical steam reforming process of light hydrocarbons, mainly methane, $28 \%$ from the cracking of heavier hydrocarbons (oil) and 7\% from coal gasification, while only $5 \%$ of the current production is obtained by electrolysis.

- Steam reforming consists in making methane $\left(\mathrm{CH}_{4}\right)$ and water vapor $\left(\mathrm{H}_{2} \mathrm{O}\right)$ react at a temperature between 700 $1100^{\circ} \mathrm{C}$, to produce syngas (a mixture consisting essentially of carbon monoxide and hydrogen), according to the reaction:

$$
\mathrm{CH}_{4}+\mathrm{H}_{2} \mathrm{O} \rightarrow \mathrm{CO}+3 \mathrm{H}_{2}-191.7 \mathrm{~kJ} / \mathrm{mol}
$$

The heat required to activate the reaction is generally provided by burning part of the methane.

- The non-catalytic partial oxidation of hydrocarbons is the thermal transformation of heavy hydrocarbons with the aid of oxygen. The reaction is exothermic and can be expressed, for a generic hydrocarbon, in the following way:

$$
C_{\mathrm{n}} \mathrm{H}_{\mathrm{m}}+\mathrm{n} / 2 \mathrm{O}_{2} \rightarrow n C O+\mathrm{m} / 2 \mathrm{H}_{2}
$$

This process takes place by operating at significantly higher temperatures than those achieved in steam reforming (1300$1500^{\circ} \mathrm{C}$ ) and this leads to a decrease in efficiency, of approximately $50 \%$.

- Coal gasification consists of a partial oxidation reaction of carbon, which is initially reduced to powders of less than 1 $\mathrm{mm}$ in size and then transformed into a gaseous fuel. The gas thus obtained, in turn, is chemically transformed into a mixture that contains hydrogen and carbon monoxide and at the end of the process is treated in order to isolate and purify the hydrogen.

- The electrolysis of water allows the splitting of the water molecule into oxygen and hydrogen, which through the passage of electric current become ions, flowing respectively towards the cathode and anode, where with exchanges of electrons they form the molecules of the respective gases:

$$
\mathrm{H}_{2} \mathrm{O}+\text { electricity } \rightarrow \mathrm{H}_{2}+1 / 2 \mathrm{O}_{2}
$$

It is the only process that does not generate greenhouse gas emissions, since its by-products are only water and heat.

Electrolysis is the most environmentally sustainable method if the electricity that powers it comes from renewable energy sources: anyway, since it is necessary to produce low-cost electricity, this is possible only by using RES.

\section{STORAGE AND TRANSPORT}

Hydrogen can be stored in a gaseous, liquid or adsorbed form in metal hydrides [21].

It can also be transported in gaseous form through gas pipelines with characteristics suitable for its physical properties: being odorless, colorless and highly flammable, it requires the installation of sensors for control; moreover, tankers can be used.

There is no fully satisfactory transport technique for efficiency, practicality, cost-effectiveness: the choice depends on the application and is a compromise between physical, 
technical, economic and safety characteristics (e.g. weight and volume are important in mobile applications, especially small ones, less for stationary ones, such as filling stations, constructions, etc.).

The most common form of accumulation is that of compressed gas, at pressures of 200-250 bar, which is the simplest and most economical: however the tanks must undergo a considerable increase in weight to withstand greater mechanical stresses.

Hydrogen can also be stored in liquid form, at a temperature of $-253^{\circ} \mathrm{C}(20 \mathrm{~K})$ (liquid hydrogen is the fuel used in NASA's space programs): for the same amount of energy stored in liquid form, the gas weighs less than all other fuels (2.7 times less than petrol), but occupies a greater volume (3.8 times more than petrol).

The disadvantages of this storage method are:

a) the need to maintain low temperatures to avoid evaporation losses (which cannot be eliminated), requiring highly efficient insulation, that increases the tank weight and its cost

b) the energy spent on liquefaction is approximately $38 \%$ of that obtained (after helium it is the most difficult gas to liquefy), with an increase in costs.

Finally, hydrogen can chemically bind with different metals and metal alloys forming hydrides, solid compounds that form when it spreads in the metal crystal lattice, occupying the interionic space if the gas is under pressure (25-100 bar): this technology allows to achieve energy densities greater than those obtainable with compressed hydrogen and comparable to those of liquid one. The advantages are economic convenience, reduced size, stability and safety due to low pressures, the disadvantage the weight.

Other storage methods that exploit gas absorption properties use crystal microspheres $(30-150 \mu \mathrm{m})$ having the consistency of dust, or carbon nanostructures, molecular structures (nanotubes, $1 \div 1.2 \mathrm{~nm}$ ).

In summary, compared to an accumulation of the same energy of another fuel, that of hydrogen is:

- much more voluminous, whether gaseous or liquid

- much heavier if hydride.

\section{USE}

Its main uses are as fuel:

- for transportation

- for the generation of electricity

which take respectively place:

- in internal combustion heat engines

- in fuel cells for electricity production (both in stationary systems or in vehicles).

Currently the main use as a fuel occurs in NASA's space programs. Other uses as an energy source occur mainly in plants in the petrochemical industries.

Hydrogen can supply energy at all scales, from micro-powers for small devices to multi-MW power plants.

\subsection{Use in fuel cells}

The use of fuel cells can affect multiple sectors and applications, including stationary (electrical production, air conditioning), mobile (transport) and portable [22, 23].

\subsubsection{Fuel cells}

Fuel cells are not new - indeed their invention precedes that of the internal combustion engine - but they did not attract interest from an industrial point of view until the sixties, when NASA decided to use them in its space program to supply electricity to spacecraft (the Apollo lunar mission used fuel cells, later adopted also in the shuttle).

Fuel cells are electrochemical devices that through a reaction between a fuel (hydrogen) and an oxidant (oxygen or air) convert the chemical energy of the fuel into electrical energy in DC and heat. The fuel or comburent molecules are broken into positive ions and electrons which, passing through an external circuit, supply an electric current proportional to the reaction speed. The reaction is inverse to that of electrolysis and the operation similar to that of electric batteries.

A cell consists of a negatively charged anode, a positively charged cathode and an electrolyte in the medium, composed of an alkaline or hydro-acid solution or a plastic membrane that allows the electrically charged hydrogen atoms to pass from the atom to the cathode.

The supply of hydrogen takes place on the side of the anode, where a chemical reaction splits the hydrogen atom into a proton and an electron. The freed electrons come out through the external electric circuit in the form of direct electric current, while the hydrogen ions (protons) travel through the electrolytic layer towards the positively charged cathode. The flow of electrons returns to the cathode, where it reacts with the hydrogen ions and oxygen in the air to form water.

The only products it generates are direct current electricity, heat and distilled water.

The fuel cell, unlike the battery, is only a conversion system batteries, in fact, store chemical energy and convert it into electricity, so when energy runs out they are discharged, on the contrary the cell is only a converter and the storage has place in an external tank.

They therefore do not store chemical energy but convert that of a fuel which feeds them by generating electricity: consequently they do not have to be recharged, but continue to generate electricity as long as the fuel and the oxidant are supplied.

While in a battery the electrodes are consumed during the discharge phase and regenerated in the recharging phase, a fuel cell produces energy as long as a reagent is supplied to the electrodes, which do not wear out but constitute only the support for chemical reactions.

The choice of fuels is very limited, since it is difficult to ionize their molecules due to the need of significant quantities of energy: hydrogen easily ionizes as the covalent bond between its two atoms is relatively weak, much more than that of methane molecule between hydrogen and carbon atoms. Furthermore, hydrocarbons are too dirty to be used as primary fuel.

A fuel cell has no moving parts, is silent and is up to two and a half times more efficient than the internal combustion engine.

There are 6 main types of fuel cell families, classified by type of electrolyte; the choice depends on the type of application and operating conditions, such as e.g. the temperature. The most common are the PEM (Proton Exchange Membrane) with polymer electrolyte, for the advantages they offer:

- power density one order of magnitude higher than the others 
- low operating temperature $\left(70-85^{\circ} \mathrm{C}\right)$

- start and achievement of half nominal power almost immediate (full power in 3 minutes)

- high returns $(60 \%)$.

\subsection{Low environmental impact cars}

A sector of strong interest for the use of hydrogen is that of cars with reduced environmental impact [24-27]:

- hybrids (heat engine plus electric motor)

- pure electric (battery operated)

- hydrogen fueled

a) internal combustion

b) fuel cells.

Hybrid cars use two different technologies:

a) with interacting engines: in which part of thermal energy produced by the petrol engine is converted into electricity to supply the batteries

b) with interacting motors plug-in version: where batteries have greater autonomy and are rechargeable via electric cable (the most used are 24-30 kWh lithium-ion)

Pure electric cars use only the electric motor, taking energy from batteries.

As for hydrogen fueled cars, the first category uses it as a fuel in conventional internal combustion heat engines, making only a few modifications to adapt them to hydrogen combustion. It is necessary:

- to reprogram the control unit to adapt the injection pressure and other gas ignition parameters

- to provide a system of sensors that avoids gas selfcombustion during the suction phase

- to eliminate turbulence in the combustion chamber, favorable in traditional engines but unwanted in hydrogen ones.

The advantages of hydrogen combustion compared to conventional fuels (petrol, diesel, methane, LPG) are:

- use of very lean mixtures (air in excess of the value foreseen by the stoichiometric air/fuel ratio), with lower emissions

- more complete combustion

- lower combustion temperature, with faster ignition

- fuel economy

- high self-ignition temperature, increasing the combustion ratio and the efficiency

- more constant efficiency.

The advantage of a hydrogen internal combustion engine is that it can be used already in a short time, requiring only simple modifications to already consolidated technologies, with the benefit of eliminating immediately the polluting emissions of $\mathrm{CO}$ and greenhouse gas $\left(\mathrm{CO}_{2}\right)$; the disadvantage is the release of nitrogen compounds into the atmosphere.

Hydrogen fuel cell electric cars are born as an evolution of pure electric cars, to overcome the problems of massive size of the battery pack and long charging times.

Usually their traction architecture is hybrid, and simultaneously uses fuel cells that produce direct current and batteries, which they recharge. The batteries mainly supply the current necessary for traction, guaranteeing a better capacity of the system to respond to operating transients (acceleration, braking, etc.), allowing a longer fuel cell life.

The efficiency of the cells is significantly higher than that of hydrogen internal combustion engines, whose low combustion temperature makes them less efficient and whose moving mechanical parts dissipate a lot of energy in friction.

A car with methane, petrol, diesel, ethanol, methanol can also produce hydrogen on-board (reformers installed in the car): although this solution uses fuel more efficiently than a traditional heat engine (fuel consumption of $40 \mathrm{~km} / \mathrm{l}$ ) fuels deriving from hydrocarbons are still used, generating emissions even if reduced.

\section{CONCLUSIONS}

In the process of decarbonization and transition to a green economy, based on a new model of distributed and sustainable energy production, hydrogen plays an important role thanks to its properties: it does not generate greenhouse gases, is versatile and has high combustion efficiency.

The new energy paradigm that should be established in the coming decades will be in fact based on micro-generation distributed from renewable sources (small electricity production plants, isolated or interconnected, placed at the end user), energy storage and, most likely, hydrogen.

Production from RES, characterized by variable and unpredictable temporal availability over time, can efficiently meet needs if coupled with storage systems: it follows that thanks to its energy performance and its environmental sustainability, the interest in hydrogen as energy carrier is today growing. It can supply energy at all scales, from micropowers for small devices to multi-MW power plants.

The paper illustrates the characteristics and properties of hydrogen, together with its production and storage techniques and uses, highlighting how, thanks to its environmental sustainability, it could play the role of energy carrier of the future in a new decarbonized energy paradigm.

However, since its infrastructures are fundamental for a rapid and effective market penetration and are still lacking, presently the cost of its use is high: consequently, in order to obtain effective and rapid market penetration, incentive policies are required, attributing to its production tariffs covering additional costs due to production, accumulation and conversion.

\section{REFERENCES}

[1] Stocker, T., Qin, D., Plattner, G.-K., Alexander, L., Allen, S., Bindoff, N., Breon, F.M., Church, J., Cubasch, U., Emori, S., Forster, P., Friedlingstein, P., Gillett, N., Gregory, J., Hartmann, D., Jansen, E., Kirtman, B., Knutti, R., Krishna Kumar, K., Lemke, P., Marotzke, J., Masson-Delmotte, V., Meehl, G., Mokhov, I., Piao, S., Ramaswamy, V., Randall, D., Rhein, M., Rojas, M., Sabine, C., Shindell, D., Talley, L., Vaughan, D., Xie, S.P. (2013). Technical Summary. In: Climate Change 2013: The Physical Science Basis. Contribution of Working Group I to the Fifth Assessment. Report of the Intergovernmental Panel on Climate Change. Ed. by T. Stocker, D. Qin, G.-K. Plattner, M. Tignor, S. Allen, J. Boschung, A. Nauels, Y. Xia, V. Bex, and P. Midgley. Cambridge, United Kingdom and New York, NY, USA: 
Cambridge University Press. Chap. TS, 33-115. https://doi.org/10.1017/CBO9781107415324.005

[2] OJEU (2009). Directive 2009/28/EC, On the promotion of the use of energy from renewable sources. Official Journal of the European Union, L140/16, 63-73.

[3] European Commission (2014). Commission Communication for a policy framework for climate and energy from 2020 to 2030 - com 0015.

[4] European Commission (2012). Energy Roadmap 2050, European Union.

[5] Gonçalves da Silva C. (2010). Renewable energies: Choosing the best options. Energy, 35(8): 3179-93. https://doi.org/10.1016/j.energy.2010.03.061

[6] Foley, A., Olabi, A.G. (2017). Renewable energy technology developments, trends and policy implications that can underpin the drive for global climate change. Renewable and Sustainable Energy Reviews, 68(Part 2): 1112-1114. https://doi.org/10.1016/j.rser.2016.12.065

[7] Narayanan, A., Mets, K., Strobbe, M., Develder, C. (2019). Feasibility of $100 \%$ renewable energy-based electricity production for cities with storage and flexibility, Renewable Energy, Elsevier, 134(C): 698709, https://doi.org/10.1016/j.renene.2018.11.049.

[8] Vad Mathiesen, B., Duić, N., Stadler, I., Rizzo, G., Guzović, Z. (2012). The interaction between intermittent renewable energy and the electricity, heating and transport sectors. Energy, 48: 406-414, Elsevier. https://doi.org/10.1016/j.energy.2012.10.001

[9] Krajacic, G., Loncar, D., Duic, N., Zeljko, M., Arantegui, R.L., Loisel, R., Raguzin, I. (2013). Analysis of financial mechanisms in support to new pumped hydropower storage projects in Croatia. Applied Energy, 101: 161171. https://doi.org/10.1016/j.apenergy.2012.07.007

[10] Avril, S., Arnaud, G, Florentin, A., Vinard, M. (2013). Multi-objective optimization of batteries and hydrogen storage technologies for remote photovoltaic systems. Energy, $\quad 35(12): \quad 5300-5308, \quad 2010$. https://doi.org/10.1016/j.energy.2010.07.033

[11] Lorestani, A., Ardehali, M.M. (2018). Optimization of autonomous combined heat and power system including PVT, WT, storages, and electric heat utilizing novel evolutionary particle swarm optimization algorithm. Renewable Energy, 119: 490-503. https://doi.org/10.1016/j.renene.2017.12.037

[12] Knut, A. (1998). Hydrogen production by electrolysis. In: Hydrogen power: theoretical and engineering solutions. Proceedings of the HYPOTHESIS II Symposium, Grimstad, Norway, London: Klewer Academic Publishers, Ed T.O. Saetre. https://doi.org/10.1007/97894-015-9054-9 11

[13] Kelly, N.A. (2014). Hydrogen production by water electrolysis. Advances in Hydrogen Production Storage and Distribution, 159-185. https://doi.org/10.1533/9780857097736.2.159

[14] Marino, C., Nucara, A., Pietrafesa, M. (2015). Electrolytic hydrogen production from renewable source, storage and reconversion in fuel cells: The system of the
Mediterranea University of Reggio Calabria. Energy Procedia, 78: 818-823. https://doi.org/10.1016/j.egypro.2015.11.001

[15] Yilanci, A., Dincer, I., Ozturk, H.K. (2008). A review on solar-hydrogen/fuel cell hybrid energy systems for stationary applications. Progress in Energy and Combustion Science, 35(3): 231-244. https://doi.org/10.1016/j.pecs.2008.07.004

[16] Momirlana, M., Veziroglu, T.N. (2005). The properties of hydrogen as fuel tomorrow in sustainable energy system for a cleaner planet. International Journal of Hydrogen Energy, 30(7): 795-802. https://doi.org/10.1016/j.ijhydene.2004.10.011

[17] Marchenko, O.V. Solomin, S.V. (2015). The future energy: Hydrogen versus electricity. International Journal of Hydrogen Energy, 40(10): 3801-3805. https://doi.org/10.1016/j.ijhydene.2015.01.132

[18] Ball, M., Weeda, M. (2015). The hydrogen economy Vision or reality? International Journal of Hydrogen Energy, 40(25): 7903-7919. https://doi.org/10.1016/j.ijhydene.2015.04.032

[19] Dincer, I., Rosen, M.A. (2011). Sustainability aspects of hydrogen and fuel cell systems. Energy for Sustainable Development, 15(2): 137-146. https://doi.org/10.1016/j.esd.2011.03.006

[20] Nikolaidis, P., Poullikkas, A. (2017). A comparative overview of hydrogen production processes. Renewable and Sustainable Energy Reviews, 67: 597-611. https://doi.org/10.1016/j.rser.2016.09.044

[21] Demir, M.E., Dincera, I. (2018). Cost assessment and evaluation of various hydrogen delivery scenarios. International Journal of Hydrogen Energy, 43(22): 10420-10430.

https://doi.org/10.1016/j.ijhydene.2017.08.002

[22] Hoffmann, P. (2001) Tomorrow's Energy: Hydrogen, Fuel Cells and the Prospects for a Cleaner Planet. Cambridge, Massachusetts: The MIT Press, 2001. https://doi.org/10.1017/S1466046602251261

[23] Marino, C., Nucara, A., Pietrafesa, M., Tripodi, A. (2015). Hydrogen production from RES, storage and reconversion in fuel cells. Proceedings of the $14^{\text {th }}$ International Building Simulation Conference, Hyderabad, India.

[24] Sustainable Vehicles Technologies - Driving the Green Agenda (2013). Proceedings of IMechE's Sustainable Vehicle Technologies 2012 conference Elsevier.

[25] Genovese, A., Ortenzi, F., Villante, C. (2015). On the energy efficiency of quick DC vehicle battery charging. World Electric Vehicle Journal, 7(4): 570-576. https://doi.org/10.3390/wevj7040570

[26] Rossi, E., Villante, C. (2011). A hybrid city car. IEEE Vehicular Technology Magazine, 6(4): 24-37. https://doi.org/ 10.1109/MVT.2011.942807

[27] Cipollone, R., Di Battista, D., Marchionni, M., Villante, C. (2014). Model based design and optimization of a fuel cell electric vehicle. Energy Procedia, 45: 71-80. https://doi.org/10.1016/j.egypro.2014.01.00 